of ophthalmology in Philadelphia and in the States during the past 100 years. This work was reviewed in our columns in Vol. XVI, p. 115, by his intimate friend, Mr. Treacher Collins.

Posey and Spiller's "The Eye and the Nervous System " was published in 1906 and was at once recognized as a pioneer work in this subject, while his "Hygiene of the Eye," published in 1918 , is a classic.

Posey was President of the American Ophthalmological Society in 1929; he was also a very active member of the National Society for the Prevention of Blindness, and became a member of its Board of Directors in 1922. Probably the last thing he wrote was the article published in the Sight-Saving Review this summer. The title is "The romance in the movement for the Prevention of Blindness," and in it he traces the history of the movement from the days when Benjamin Gibson of Manchester emphasized the connection, hinted at by Quellmaltz about half a century earlier, between 'babies' sore eyes' and vaginal discharge in the mother. Gibson's work was not recognized at the time, and so late as 1837 we find the Spanish Cortes decreeing that babies be baptized " with warm water, since the cold water commonly employed was so often followed by sore eyes and in many cases by blindness."

The work of Credé and of Ernst Fuchs, Lucien Howe, Park Lewis and the Misses Edith and Winifred Holt with that of Louisa Lee Schulyer is noticed.

We are indebted to Mr. Lewis Carris for sending us a clipping from the New York Times of September 6, and a reprint of Posey's last article.

Much sympathy will be felt for Dr. Posey's widow and children; his untimely death is a heavy blow to ophthalmology.

\title{
ARTHUR ZORAB
}

WE much regret to record the death of $\mathrm{Mr}$. Zorab of Southampton, which occurred at the end of August, 1934. Mr. Zorab was born in 1880 , the son of Col. Zorab, I.M.S.; he was educated at Guy's Hospital and took the conjoint diploma in 1906, graduating M.B., B.S. at the University of London in the same year. Settling at Southampton he rapidly made his mark as an ophthalmic surgeon. $\mathrm{He}$ was Hon. Surgeon to the Southampton Eye Hospital and Ophthalmic Surgeon to the Royal Hants. County Hospital at Winchester. Mr. Zorab was a member of the Ophthalmolgical Society of the United Kingdom and Oxford Congress, and had been chief assistant in the Ophthalmic Department at Guy's 
Hospital, and at one time Lieut. I.M.S. He was the author of several papers in the Transactions, and in our columns; his most notable contribution being his work with Mayou on Aqueoplasty, published in 1912.

We understand that he was at work until the end in spite of indifferent health. Much sympathy will be felt for his widow and relatives.

\section{NOTES}

Royal Eye Hospital Scholarship

Applications are invited for the research scholarship tenable at the Royal Eye Hospital, St. George's Circus, S.E.1, and are to be received by November 14 . The value of the scholarship is $£ 100$ per annum.

\section{Hunterian Lecture}

Mr. B. W. RYCROFT was elected a Hunterian Professor at the Royal College of Surgeons in July, 1934. His lecture will be delivered on January 28,1935 , at 5 p.m. The title is "Recent Investigations in the Aetiology and Treatment of Glaucoma."

National Society for
the Prevention of
Blindness, Inc. Comittee of the Society, Mr. Clark having been chosen Treasurer. Dr. Edward Jackson has become a Director of the Society and Dr. P. W. Cobb a member of the Editorial Committee of the "Sight-Saving Review."

\section{FUTURE ARRANGEMENTS}

\section{4}

November 9.-Section of Ophthalmology, Royal Society of Medicine. November 16.- North of England Ophthalmological Society, at Bradford. 